\title{
REFERENCIAÇÃO E PROGRESSÃO TÓPICA: ASPECTOS COGNITIVOS E TEXTUAIS ${ }^{1}$
}

\author{
LUIZ ANTÔNIO MARCUSCHI \\ (UFPE)
}

\begin{abstract}
This paper analyzes the relation between topic progression (maintenance of theme) and referetiation (process of the organization of referents) throughout a text. From a cognitive point of view we know that the user's (producers and receivers) task is made more difficult if the investiment in shared knowledge and new knowledge is not managed with equilibrium. Therefore, we postulate that textual progression and its correlation with stable cognitive models is a complex activity of explicitation realized by means of repetition, cognitive pressupposition, lexical selection, syntactic decisions, and so forth. This study, then, is an attempt to define parameters taken from textual production that are valid for a set of differentiated discursive genres.
\end{abstract}

\section{O PROBLEMA}

De uma maneira geral, pode-se distinguir, na tradição dos estudos semântico-discursivos, duas tendências básicas no tratamento da referência. A primeira, mais antiga e ainda predominante nos estudos lógico-semânticos, bem como nas análises naturalistas da linguagem, é a que se funda numa concepção de linguagem como transparente e referencialista, tendo por base uma visão instrumentalista de língua. Esta posição garante uma relação clara entre linguagem e mundo e vem sendo postulada pelas teorias vericondicionais, entre outras. A segunda posição postula uma noção de linguagem como atividade sócio-cognitiva em que a interação, a cultura, a experiência e aspectos situacionais interferem na determinação referencial. Ressalte-se que esta segunda posição não se confunde com o nominalismo².

De especial interesse no caso da primeira perspectiva teórica, é a crença na possibilidade de dizer o mundo de forma objetiva, distinguindo rigidamente entre fatos e crenças. Além disso, essa perspectiva caracteriza-se por produzir teorias da compreensão e da produção textual em que, de um lado, está o texto com conteúdos objetivamente inscritos e, de outro, indivíduos que, em condições específicas, podem captar os conteúdos sem maiores problemas. Para estes autores, tanto a linguagem como o mundo estão previamente discretizados e podem ser correlacionados biunivocamente. A referência, seria, neste caso, uma contraparte extra-mente para um conceito ou uma expressão lingüística. Os referentes, nesta teoria, são objetos do mundo e a atividade de referi-los é um processo de designação extensional.

${ }^{1}$ Texto publicado na Revista do GELNE (2000), vol. 2, no 2, pp. 55-65.

${ }^{2}$ Gostaria de postular, de maneira enfática, tal como o faz Nunberg (1976:2), logo no início de sua tese sobre "A Pragmática da Referência", que "knwoledge of word-meanings can only be treated as an inseparable part of knowledge of other kinds of conventions and social practices, from which it cannot, even in theory, be isolated." 
Já no caso da teoria que toma a língua como atividade e postula o texto como um evento em que convergem ações de natureza lingüística, social e cognitiva, como lembra Beaugrande (1997), não se admite que os referentes sejam sistematicamente objetos do mundo, tendo em vista que se caracterizam como objetos de discurso, segundo largamente postulado, por exemplo, por Mondada (1994) e muitos outros. É nesta segunda posição que nos situamos para resolver a questão da relação entre processos refenciais (referenciação) e organização tópica (coerência) na atividade discursiva. Aqui os sentidos fundam-se numa atividade de interação e co-produção em que os conhecimentos partilhados têm um papel crucial.

Neste estudo, será observado como a explicitação, a repetição, a pressuposição cognitiva, a seleção lexical, as decisões sintáticas, entre outras, podem ser analisadas na sua relação com a progressão tópica e a referenciação tomadas no quadro teórico sugerido. A expressão referenciação passa a ser usada no lugar de referência, já que esta última tem um caráter de relação pré-fabricada (à margem das condições de uso) entre o mundo e a linguagem. Tal como observa Mondada (1994:17), ao se considerar a noção de

"objeto de discurso interessa ter em conta a imbricação das práticas cognitivas e sociais nas operações de referenciação, onde a referência é construída pela atividade enunciativa e orientada em primeiro lugar para a dimensão intersubjetiva no seio da qual ela é negociada, instaurada, modificada, ratificada."

Para autora, como para nós, mais do que "a maneira como o texto faz referência a uma exterioridade", interessa "a maneira como os locutores concebem sua referência a uma exterioridade" (p. 17). Isto significa que é essencialmente na interação que se constroi o sentido.

A coerência e a continuidade tópica num discurso não são algo dado informacionalmente por fatores externos nem algo que se produz numa relação de continuidade linear de relações morfossintáticas e designações fixas. Constituem um resultado assegurado pelo acesso fornecido com base numa suposição de partilhamento de conhecimentos invocados para identificar referentes. Neste caso, nosso maior desafio será o de manter a noção de tópico, apesar de sua fragilidade e instabilidade, tendo sempre em vista que ele é construído pelos objetos de discurso.

Com isto, busco interligar uma série de questões com base numa postura a uma só vez cognitiva, discursiva e interativa. Imagino que não será fácil contornar todos os problemas aqui envolvidos, mas suponho que se trate de um caminho razoável para resolver as questões que o título desta exposição evoca.

\section{NOÇÃO DE TÓPICO}

A noção de tópico continua problemática e pode ser entendida de acordo com os contextos teóricos em que é utilizada. Uma distinção usualmente feita neste caso é entre tópico frasal e tópico discursivo. O primeiro é de natureza sintática e se restringe ao nível da frase, tal como postulado inicialmente pela Escola de Praga na distinção hoje retomada por vários autores entre tema e rema. Assim, a noção funcional de tópico (equivalente ao tema), embora de cunho essencialmente semântico-pragmático, é de natureza sintática e em certo sentido equivale ao sujeito do enunciado, por ser aquilo sobre o qual se fala. Contudo, não se confunde com o sujeito sintático da frase e pode ser caracterizado pela entoação ou por um processo de alçamento chamado topicalização. Trata-se de uma visão em que forma e função são conjugadas no processo de linearização discursiva. Costuma-se, em outros contextos teóricos, distinguir entre tópico e 
comentário, o que equivale a uma distinção de caráter mais pragmático, assim como o par dado e novo, de natureza mais cognitiva. Em todos os casos trata-se de uma distinção sintática que faz uma ponte entre o semântico e pragmático no âmbito da frase.

Neste estudo, deixo de lado a noção de tópico frasal para adotar a noção de tópico discursivo, que designa macro-estruturas semânticas (tal como postulado por Van Dijk, 1977) ou o tema discursivo, aquilo sobre o que se está falando num discurso (tal como sugerido por Brown \& Yule, 1983), não necessariamente considerando a frase. Para este tipo de tópico a unidade é o discurso e não a frase. Aqui não se costuma distinguir entre tópico discursivo e outro pólo, como no caso das distinções anteriores. De natureza mais holística e heurística, o tópico discursivo é levado adiante em porções maiores e se desenvolve nos processos enunciativos. No caso de uma interação face a face, por exemplo, ele é desenvolvido interativamente. Pode ser introduzido, desenvolvido, retirado, reintroduzido, reciclado ou abortado (cf. a análise das ações tópicas segundo Bublitz).

Tal como vista acima, a noção de tópico frasal restringe-se ao plano frástico e não se presta a uma abordagem discursiva. Isto porque trata apenas da relação coesiva imediata (localizada e linear), fazendo com que a coerência pareça uma relação semântica ou fundada no conteúdo, privilegiando uma visão informacional da língua. De certo modo, a noção de tópico frasal só dá conta da continuidade ou da boa formação semântica passo a passo, sem poder explicar as descontinuidades a não ser negativamente. Já a noção de tópico discursivo permite tratar de mais aspectos, inclusive da continuidade-descontinuidade discursiva em termos mais globais e até mesmo a passagem de tópicos antigos para novos. Com esta segunda noção se pode dar conta de fenômenos tipicamente discursivos tais como as interrupções ou as intenções fundadas em estratégias de manipulação tópica. Isto é de especial interesse para a explicação das interações face a face, como se pode observar no trabalho de Koch et alii (1990).

A noção de tópico discursivo não elimina a frase, mas considera-a sempre relacionada tanto a aspectos cotextuais como contextuais. Baseada em Chafe (1982), observa Mondada (1994:45) que "o discurso procede constantemente a ativações e desativações". Uma entidade pode ser ativada por esquemas (uma espécie de semi-ativação) e passar a um estado de acessibilidade antes de ser acessível. Do ponto de vista discursivo, uma informação ativada pode ser mantida mediante estratégias anafóricas (sejam elas pronominais ou nominais, entre outras) e com isto manter o tópico em andamento. Pode-se também manter um tópico ativo com outras estratégias, tais como processos entoacionais, seleções sintáticas ou construções paralelas, topicalizações e associações.

Em relação a esses aspectos, o discurso oral e o escrito têm organização e desenvolvimento tópico relativamente diferenciado tendo em vista suas condições de produção. A conversação, por exemplo, desenvolve a dinâmica tópica interativamente (sem um planejamento prévio e com monitoração local), ao passo que o texto escrito segue um processo enunciativo mais calculado, na base de suposições sócio-cognitivas e planejamento de maior alcance. Nisto residem algumas diferenças interessantes entre oralidade e escrita, tendo aqui o tempo e o espaço um papel importante, já que a oralidade se dá num tempo real e a escrita num tempo defasado (não só em relação à recepção, mas também em relação à produção).

Além disso, cada gênero discursivo (tanto na fala como na escrita) apresenta algumas características próprias em relação à condução tópica. Uma carta pessoal e um artigo científico, uma conversação espontânea e uma conferência acadêmica não mantêm entre si relações distintivas lineares com base na simples caracterização de oral e escrito. Quanto a isto, ainda 
MARCUSCHI - Referenciação e progressão tópica...

faltam estudos pontualizados para uma definição clara. Algumas observações já foram feita nos trabalhos do NELFE e seus resultados prévios expostos em congressos.

Considerando que o tópico sentencial (TS) é de natureza seqüencial (seqüenciação de enunciados) e que o tópico discursivo (TD) é de natureza global, temos a ver com processos seqüenciais no caso dos TS e com processos configuracionais no caso dos TD (v. Mondada, 1994:52, ao citar van Dijk, 1977). ${ }^{3}$

No caso do tópico discursivo, podemos dizer que existem certas organizações (configurações) que se manifestam em esquemas globais ou enquadres (frames) que se desenvolvem no encadeamento de elementos informacionais lexicalizados. Nosso interesse é precisamente acompanhar este desmembramento e verificar se há uma relação direta entre as organizações tópicas e as organizações lexicais e, neste caso, como ambas se relacionam na construção de todo o processo referencial e qual a colaboração de outros aspectos tais como o contexto e os conhecimentos prévios. Vejamos um simples exemplo de um texto muito breve extraído de uma publicidade.

(Exemplo 1)

\begin{tabular}{|l|l|}
\hline \multicolumn{1}{|c|}{ Texto original } & Expressões relacionadas \\
\hline $\begin{array}{l}\text { Se o forte de seu pai não é a expressão corporal, como } \\
\text { é que você vai deixar ele dançar no presente? }\end{array}$ & $\begin{array}{l}\text { pai - expressão corporal } \\
\text { dançar - presente }\end{array}$ \\
$\begin{array}{l}\text { O Seu pai é bom em tanta coisa, é tão bom pra você. Ele merece um } \\
\text { presente no Dia dos Pais. Claro que merece. O Shopping tem tudo que ele } \\
\text { quer ganhar. É só escolher. Se você deixar ele dançar no presente, do jeito } \\
\text { que ele é descoordenado, vai ser uma vergonha tão grande que você nunca } \\
\text { vai se perdoar. E muito provavelmente, ele também nunca vai perdoar você. }\end{array}$ & $\begin{array}{l}\text { presente no Dia dos Pais } \\
\text { dançar no presente = ficar sem um presente }\end{array}$ \\
\hline
\end{tabular}

A primeira parte desse texto publicitário encerra uma ambigüidade intencional na expressão "dançar no presente" resolve-se na segunda parte com a contextualização do anúncio pela especificação do "presente no Dia dos Pais". Essa publicidade tem em vista o incentivo às compras numa data comercial típica. Na primeira parte, várias expressões foram usadas com referenciações sugeridas, mas não pretendidas de fato. Assim, no caso da lexia "expressão corporal" temos apenas um mote hilariante ao lado de uma fotomontagem desproporcional (de um pai que privilegia a cabeça e não o físico), para despistar a interpretação de "dançar no presente". Na realidade, não se trata de dançar numa relação com a dança de fato, e sim com sua significação popular, gíria, no sentido de passar em branco, perder etc. Veja-se que os processos referenciais e as pistas lexicais só entram em ação na relação com um tópico discursivo.

Resumidamente, podemos dizer que a noção de tópico TD aqui adotada diz respeito à produção enunciativa dos objetos de discurso mediante modos de enuciação sociocognitivamente situados. A sugestão sistemática proposta é a de que quando usamos a língua para produzir nossas enunciações discursivas, não estamos apenas transformando objetos do mundo em objetos de discurso, mas estamos produzindo objetos de discurso. Do contrário, continuaríamos presos a uma visão de linguagem como atividade codificadora de informações objetivas.

3 "Os tópicos sentenciais... determinam a distribuição da informação ao longo das sequências, enquanto os tópicos discursivos parecem reduzir, organizar e categorizar informações semânticas de sequências com um todo". (Van Dijk, 1977:132) 


\section{APROFUNDANDO A NOÇÃO DE OBJETOS DE DISCURSO}

Nunca teremos certeza de como é o mundo em si. Já Kant postulava esta visão com grande acuidade e imaginava que não temos acesso ao "ser em si", ou seja, ao mundo nuomênico, ao fenômeno puro, de modo que, ao termos de acessar o mundo pelo discurso, é do discurso que partimos e não do mundo como tal. Assim, faz sentido tratar aqui em detalhe este aspecto que vai além de uma visada apenas cognitiva da realidade.

Considerando a noção de tópico na forma acima, i. e., como TD, e seguindo sugestão de Mondada (1994:56), poderíamos admitir uma relação direta entre a noção a de objetos de discurso e tópico. Isto pode-se dar por várias operações internas assim definidas: ${ }^{4}$

1. Operações de enquadre: uma determinada expressão pode evocar um conjunto de propriedades, relações ou associações (frames, cenários, esquemas etc);

2. Operações de textualização: são relações determinadas pelo domínio cognitivo gerado no processo de textualização de um elemento (cotextualidade);

3. Operações de referenciação: um elemento designa um universo e fenômenos nomeados por sinonímia ou até mesmo por substituição.

Essas operações têm a propriedade de determinar domínios referenciais conduzidos lexicalmente ou discursivamente para construir configurações mais gerais. Com isto ultrapassase a simples coesão pelo encadeamento de elementos linearizados, seja por processos anafóricos ou outros de ligações sequenciais locais, gerando formações mais globais e de longo alcance.

Basta um breve exemplo para identificar como isto ocorre. Trata-se de uma versão levemente mudada do conto da Chapeuzinho Vermelho. 5

(Exemplo 2)

\begin{tabular}{|c|c|}
\hline $\begin{array}{l}\text { Chapeuzinho vermelho } \\
\text { (versão popular) }\end{array}$ & $\begin{array}{l}\text { Elementos que conduzem } \\
\text { as operações discursivas }\end{array}$ \\
\hline $\begin{array}{l}\text { Chapeuzinho Vermelho está andando pela floresta, para levar } \\
\text { seus docinhos para vovozinha, quando vê uma moita se mexendo. } \\
\text { Sem conseguir conter sua curiosidade, espia atrás da moita e dá } \\
\text { de cara com o Lobo Mau. } \\
\text { - Bom dia seu Lobo! Nossa que olhos grandes você tem! - } \\
\text { observa ela. } \\
\text { São para melhor te ver, Chapeuzinho! - respondeu o Lobo, } \\
\text { cordial. } \\
\text { E ela continua o seu passeio. Pouco mais adiante, vê outra moita } \\
\text { se mexendo. Corre para dar uma espiada e novamente encontra o } \\
\text { Lobo Mau. }\end{array}$ & $\begin{array}{l}\text { Chapeuzinho Vermelho } \\
\text { Vovozinha - moita se mexendo } \\
\text { Lobo Mau } \\
\text { Olhos grandes } \\
\text { melhor te ver } \quad \text { cordial }\end{array}$ \\
\hline
\end{tabular}

\footnotetext{
${ }^{4}$ Sigo aqui sugestões de Grize, 1983, tal como lembrado por Mondada (1994:59).

${ }^{5}$ Essa versão me foi fornecida pela aluna de Graduação em letras da UFPE, Polyanna Angelote Camelo e coletada por ela e Alexandra Farias Santiago na Internet, não se registrando a autoria.
} 


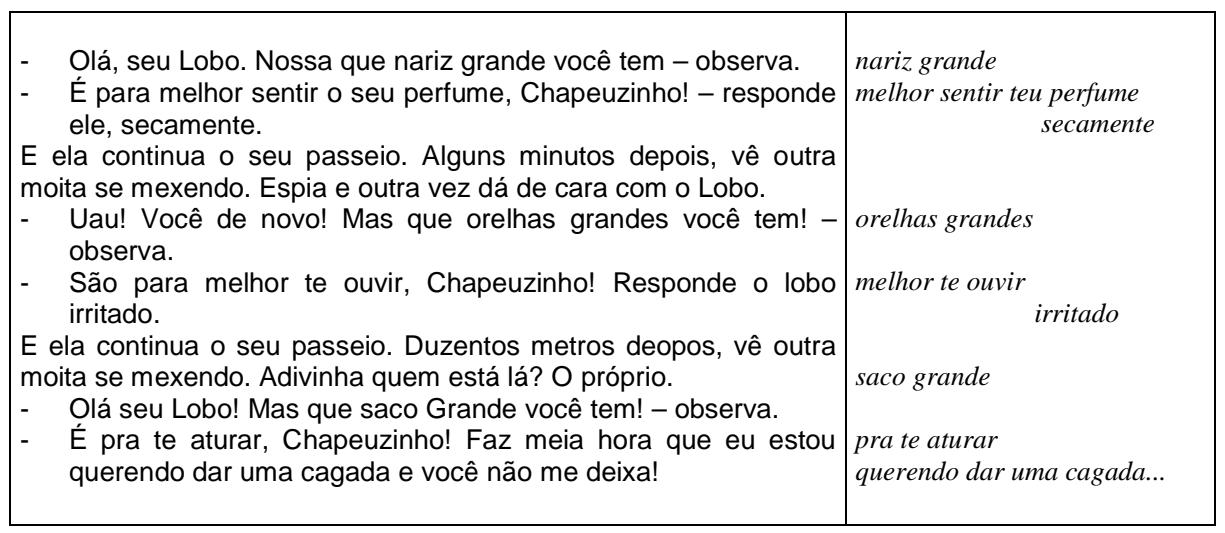

Note-se que, sob o ponto de vista dos três conjuntos de operações designados acima temos:

(a) operações de enquadre: as expressões Chapeuzinho Vermelho, Vovozinha e Lobo Mau, olhos grandes, orelhas grandes, nariz grande carregam em si uma série de expectativas para todos os que conhecem este conto. Não se trata propriamente dos mesmos personagens da conhecida história, mas de uma versão livre e talvez sem os ingredientes esperados.

(b) operações de textualização: os elementos comentadores (que acompanham cada resposta do Lobo Mau, indo do cordial ao secamente e o irritado, acabando no esculacho).

(c) operações de referenciação: este tipo de operação introduz certos elementos que levam a outros indícios: moita, caminhada, saco grande, etc. desginados para fazer a história andar.

Não há como negar que aqui se desenvolve uma atividade enunciativa por um processo sócio-cognitivo que ultrapassa a necessidade de uma relação direta linguagem-mundo para produzir o interdiscurso numa intertextualidade evocada por personagens e situações construídos sem nenhuma realidade externa e até na subversão do protótipo tradicional, seja o de Perrault ou o dos irmãos Grimm. Contudo, isto não deve conduzir à idéia de que construímos o mundo de modo exclusivamente discursivo, pois se estas operações internas (em boa medida realizadas na cotextualidade e no plano de um código) são fundamentais, elas não podem eliminar o concurso de fatores externos (tal como a pré-existência de uma narrativa). Sabemos, no entanto, que a Chapeuzinho Vermelho e o Lobo Mau desta narrativa não correspondem aos da narrativa tradicional, mas é com base neles que construímos a referenciação e as expctativas desta nova versão.

Assim, a questão empírica não desaparace, mas assume um lugar definido e delimitado. Os objetos de discurso (enquanto espaços mentais) não são dados exclusivamente discursivos, pois eles emergem de uma inspiração do mundo sob um fundo existente (espaços de base) e inserem-se num mundo pensável. O discurso é esse movimento dinâmico que permite o surgimento dos objetos nele desenvolvidos.

Ao adotar a noção de objeto de discurso sigo, segundo frisado, a sugestão de Mondada (1994:62), que utiliza a expressão "objeto de discurso" ao invés de "objeto do discurso", 
Cadernos de Estudos Lingüísticos 48(1) - Jan./Jun. 2006

como o fazem outros autores (Grize, p. ex., utiliza ambas indistintamente). A expressão 'objeto de discurso' faz referência ao fato de que os objetos tratados no discurso, ou seja, aqueles elementos aos quais o discurso faz referência (i.e. os objetos do discurso) são "objetos constitutivamente discursivos" e, como tal, "objetos de discurso" gerados na produção discursiva, na enunciação, no processo lingüístico. Portanto, a expressão "objeto de discurso" faz referência clara ao caráter discursivo dos objetos introduzidos no discurso. No dizer de Mondada (1994:62):

"é no e pelo discurso que que são postos, delimitados, desenvolvidos, transformados, os objetos de discurso que não lhe preexistem e que não têm uma estrutura fixa, mas que ao contrário emergem e se elaboram progressivamente na dinâmica discursiva."

Em suma, os objetos de discurso não são uma simples remissão lingüística a algo autônomo, fixo, externo e prévio ao discurso. Neste sentido, também deve ficar claro (como se verá adiante) que não uso a noção de referência e sim de referenciação precisamente pelo fato de admitir que a atividade referecial não é pura e simplesmente o ato de designar lingüisticamente objetos do mundo.

Os objetos de discurso são dinâmicos, isto é, podem ser introduzidos e depois modificados, desativados, reativados ou reciclados em "movimentos discursivos" (Mondada, 1999:64). Introduzidos linguisticamente, os objetos de discurso não se esgotam neste aspecto, mas se desenvolvem discursivamente categorizando os objetos ou recategorizando-os. Com isto, contribuem para a construção progressiva do tópico discursivo sem se ater a categorias já determinadas.

\footnotetext{
"O objeto de discurso caracteriza-se pelo fato de construir progressivamente uma configuração ao se enriquecer com novos aspectos e propriedades, suprimir antigas ou ignorar outras possíveis, que ele pode associar com outros objetos integrando-se em novas configurações, ou se articulando em partes susceptíveis de se autonomizarem em novos objetos. O objeto se completa discursivamente." (Mondada, 1994:64).
}

Esta postura sugere uma noção dinâmica de discurso. O problema a ser resolvido é da administração desse aspecto. No caso de diálogos, por exemplo, em que a atividade discursiva é interativa e colaborativa, num processo de co-construção, os objetos de discurso têm percursos e dinâmicas diversos do que no caso dos discursos monologais, escritos ou orais. Trata-se de um processo de construção dinâmico por operações discursivas em que o discurso está sempre se "fazendo", isto é, construindo.

\section{A NOÇÃO DE REFERENCIAÇÃO E O PROBLEMA DA CATEGORIZAÇÃO}

Considerando o que se disse acima sobre a noção de objeto de discurso, podemos admitir a referenciação como um processo de geração de domínios referenciais com objetos discursivos para referir-se a um estado do mundo. Neste caso, a língua é muito mais do que simples mediadora; se explica como atividade cognitiva e não apenas como forma cognoscitiva (mapeadora) da realidade. A realidade não é um dado a priori, mas uma construção discursiva motivada. 
MARCUSCHI - Referenciação e progressão tópica...

Temos aqui uma visão de língua orientada muito mais para os modos de enunciação do que para a referência do mundo. Isto significa que não admitimos (cf. Mondada, 1994:63) uma noção realista e cartográfica da linguagem como mapeadora da realidade, ou seja, um espelhamento direto. Não se verifica uma determinação externa da língua e sim uma noção de língua como "atividade intersubjetiva na e pela qual é constituído um modelo público de mundo". ${ }^{6}$

Caso interessante e sem dúvida exemplar desse funcionamento da língua é o que se dá nas denominadas anáforas sem antecedente explícito, como já foram tratadas em Marcuschi (1998). Exemplo típico destas anáforas é o seguinte:

\section{(Exemplo 3)}

A equipe médica continua analisando o câncer do Governador Mário Covas. Segundo eles, o paciente não corre risco de vida.

Aqui, o pronome eles não tem um um referente cotextual antecedente, o que o torna nãocorreferencial. No entanto, sabemos a que é que esse pronome se refere. A atividade inferencial interpretativa funda-se, aqui, num conjunto de operações relativamente complexas e apresenta algumas características não abarcadas pela análise gramatical. É neste sentido que os processos de referenciação, condução tópica e coerência discursiva estão imbricados.

Seguramente, para solucionar o problema da referenciação, deveríamos trabalhar em detalhe os aspectos envolvidos nas atividades de categorização desenvolvidas nos processos discursivos. Isto nos remeteria a uma análise das relações entre discurso e cognição. Este terreno, embora rico e fértil em sugestões, não pode ser percorrido aqui em detalhe, já que nos conduziria a uma digressão que, embora útil, desviaria dos propósitos centrais da análise. Contudo, algumas observações se fazem necessárias.

Se por um lado, o mundo, no discurso, é um "efeito de estruturação" da atividade discursiva pelos procedimentos de desenvolvimento tópico e construção de objetos de discurso, por outro lado, não é mera fantasia cognitiva. Isto remete à necessidade de observar como categorizamos discursivamente o mundo. Muitas são as propostas neste sentido, desde Aristóteles com uma posição metafísica, até Rosch, na psicologia cognitiva e a etnometodologia, ou as posições mais recentes da lingüística cognitiva em suas diversas vertentes.

Por certo, neste contexto, não podemos admitir a posição comum de que nossa atividade cognitiva tem por missão organizar da forma mais econômica possível através da língua nossas atividades perceptivas do mundo. Pois isto nos conduziria a uma visão da língua como uma espécie de cartografia categorial da realidade extra-mente. A língua não é um burocrático cartório do mundo. As categorias construídas na observação do mundo e de sua partição, seja verticalmente em hierarquias (por exemplo, as espécies do reino animal) ou horizontalmente (por exemplo, os tipos dentro de cada espécie), apresentam problemas de delimitação, já que não temos critérios para as condições suficientes e necessárias de incluir um ou outro elemento na categoria, nem temos uma realidade homogênea à nossa frente. A saída encontrada por Rosch (1978), por exemplo, com a sugestão de protótipos, também não é suficente nem

\footnotetext{
${ }^{6}$ Observações elaboradas a partir de Mondada (1994:63) em nota (nota 45 iniciada na p.62). Contudo, saliento que esta posição não é nova nem original da autora. Trata-se de uma postura que vem desde Wittgenstein em suas Investigações Filosóficas, bem como depois, elaboradas em detalhe por I. Putnam entre outros. Ainda retornarei a estes aspectos adiante.
} 
Cadernos de Estudos Lingüísticos 48(1) - Jan./Jun. 2006

animadora porque os protótipos são no geral culturais e não naturais. A questão das categorias é algo mais complexo do que a simples mediação simbólica do mundo pela linguagem. É uma classificação e ordenação geralmente realizada sem a explicitação do princípio ordenador.

Segundo observado por diversos autores, as categorias não podem ser tomadas como estruturas invariantes capazes de realisticamente agruparem a realidade extra-mental de modo culturalmente insensível. Isto quer dizer que há, além dos contextos variáveis, também a questão da inserção cultural das categorias. As estruturas da realidade são variáveis e contínuas, não são discretas nem invariantes. Também é de lembrar que, do ponto de vista cognitivo, nossa memória categorial é em geral ad hoc, isto é, construída em adequação ao contexto em questão. A noção de exemplaridade de uma categoria não é suficiente para lhe dar estabilidade, pois numa realização cotextual ela pode evocar focalizações bem diferenciadas a depender do tipo de inserção discursiva.

Não é necesário especular muito para ver como isto ocorre. Tome-se o caso típico e comum dos processos de categorização em textos humorísticos. Recentemente, anunciava-se o fim do mundo, marcado para 11 de agosto de 1999. Foram muitas as piadas a este respeito. Veja-se, por exemplo, um texto veiculado pela Internet com as manchetes principais de cada Jornal ou revista semanal para tal anúncio (da qual extraí estes casos):

(Exemplo 4)

- Diário de Lisboa: "Leia amanhã como o mundo acabou hoje."

- O Globo: "Governo anuncia o fim do mundo."

- Jornal do Brasil: "Fim do mundo espalha terror na zona sul"

- Folha de São Paulo: (ao lado de um imenso gráfico) "Saiba como vai ser o fim do mundo"

- O Estado de São Paulo: "CUT e PT envolvidos no fim do mundo."

- Correio Braziliense: "Congresso vota constitucionalidade do fim do mundo."

- Diário Oficial da União: "Presidente faz a sua última viagem."

- Veja: "Exclusivo. Entrevista com Deus - Porque o apocalipse demorou tanto."

"Paulo Coelho: "O profeta viu o fim do mundo e chorou."

- Sexy: "Como transar no além."

- Playboy: "Nova loira do Tchan: um apocalipse de sensualidade."

- INFO Exame: "100 dicas de como aproveitar o Windows the End."

Desde que conheçamos os jornais e as revistas aqui nomeados, não há grande dificuldade de perceber que estão sendo categorizados (recaracterizados!) por algum de seus cacoetes ou pela ideologia predominante no órgão. É assim que muitas vezes não necessitamos nomear um determinado fenômeno para designá-lo ou trazê-lo para o interior do discurso. Basta um item lexical que esteja de algum modo e por alguma razão crucial ligado àquele fenômeno ou objeto ou indivíduo. Categorizar um dado fenômeno ou subsumi-lo numa categoria é situá-lo num conjunto de relações com contorno identificável. Este é o processo de enquadre cognitivo.

De um modo geral, observa Mondada (1994:78), a perspectiva da psicologia cognitiva tem privilegiado uma visão informacional da cognição no tratamento das categorias e não uma visão processual ou discursiva. Não se preocupa com a construção intersubjetiva do conhecimento, mas com a veiculação do conhecimento entre indivíduos, como se tudo não passasse de uma circulação de informações objetivas. Mas, como se observou nos exemplos 
MARCUSCHI - Referenciação e progressão tópica...

acima, o que ocorre nas categorizações ou inserções categoriais é precisamente uma identificação sócio-cultural.

A questão da categorização é interessante porque sua função cognitiva se revela muito produtiva desde que estejamos inseridos num dado contexto. Veja-se este caso que para ser entendido exige enorme grau de inserção social e contextual no momento histórico. Caso alguém não tenha conhecimento de certos fatos atuais ou personagens da sociedade brasileira atual, terá dificuldade para entender o texto a seguir, porque não percebe como se dá a categorização ali pretendida. (Os que lerem este texto daqui a cinco anos vão ter dificuldade para entender os contextos aqui evocados e não explicitados.) Trata-se de um texto de José Simão, autocognominado "Macaco Simão" e que mantém uma coluna na Folha de São Paulo. Vejamos três parágrafos de um texto recente dele:

(Exemplo 5)

\begin{tabular}{|c|c|}
\hline Galisteu fax xixi exclusivo pra "Caras"! & Galisteu - “Caras"! \\
\hline $\begin{array}{l}\text { Buemba! Buemba! Macaco Simão Urgente! Tô adorando: } \\
\text { Adriane Galisteu termina casamento e se refugia no castelo } \\
\text { de "Caras". Com oito fotógrafos, dois maquiadores, uma } \\
\text { cabeleireira, três camareiras e oito repórteres. Diz que era } \\
\text { um momento de reflexão. Só se for fazendo reflexos. } \\
\text { Momento Wellaton! } \\
\text {........... } \\
\text { E o ex-marido? O Justus? Parece senador americano de } \\
\text { minissérie. Totalmente "Dallas". E o topete? Já sei, passou o } \\
\text { casamento fazendo escova! E diz que o casamento não deu } \\
\text { certo porque ele dorme com aquela redinha de Alberto } \\
\text { Roberto! } \\
\text {........... } \\
\text { São os reis da midiocracia! E antigamente as pessoas se } \\
\text { separavam por chifre ou por grana. Depois os americanos } \\
\text { inventaram a incompatibilidade de gênios. E agora a "Caras" } \\
\text { inventou a incompatibilidade de agendas. É o mercado! }\end{array}$ & $\begin{array}{l}\text { Adriane Galisteu - } \\
\text { termina casamento - castelo "Caras" } \\
\text { momento de reflexão } \\
\text { Momento Wallaton } \\
\text { ex-marido - Senador americano de } \\
\text { minissérie - "Dallas" } \\
\text { redinha de Alberto Roberto } \\
\text { midiocracia } \\
\text { chifre ou grana incompatibilidade de gênios } \\
\text { incompatibilidade de agenda - } \\
\text { mercado }\end{array}$ \\
\hline
\end{tabular}

Como se nota, há aqui uma espécie de processo de categorização embutido por trás dessas observações jocosas do autor. Vejamos apenas três delas:

(a) momento de reflexão - momento Wellaton: há aqui uma relação entre um tipo de shampoo para mulheres com cabelos soltos (Wellaton), longos e lisos com reflexo, talvez aloiradas, tal como o caso da senhora citada no texto, que se refugia para uma "reflexão" ou reflexo? (com todo o aparato citado anteriormente, cabeleireiro, maquiador, fotógrafo...). Na verdade, o autor do texto jogou com aspectos de categorização produzidos por um produto de grande presença na mídia para uma metacategorização da expressão "reflexo". 
Cadernos de Estudos Lingüísticos 48(1) - Jan./Jun. 2006

(b) Senador americano de minissérie - "Dallas": a expressão “Dallas", nome de uma minissérie americana sobre um senador, é uma forma de categorizar um personagem da "sociedade brasileira endinheirada" mas balofa.

(c) Redinha de Alberto Roberto: utilização de um clichê formado por um personagem humorístico conhecido pela TV por sua incapacidade de entender qualquer tipo de papel ou adequação social e situacional, vivendo uma ilusão de sua suposta identidade. A redinha (que o personagem traz na cabeça para manter o cabelo) e o nome do personagem foram os dois elementos escolhidos para a categorização.

Aqui se observam como as Operações de enquadre (frames, cenários, esquemas etc); as Operações de textualização (relações determinadas pela cotextualidade) e as Operações de referenciação (universo e fenômenos sugeridos e apontados) atuam para criar personagens que só têm sentido neste discurso. Esta é uma atividade discursiva que relaciona processos de categorização à dimensão social e faz com que o processo cognitivo tenha a ver também com a atividade sócio-histórica dos indivíduos, não sendo apenas uma atividade de operação sobre percepções ou informações sensoriais. Tudo indica, pois, que os processos cognitivos se organizam socialmente e não são apenas inatos ou alheios ao envolvimento social.

A posição da etnometodologia, que visa a mostrar como se constrói a racionalidade numa dada comunidade, postula que nossas representações (categorizações) são localmente produzidas, contextualmente dependentes e lingüisticamente organizadas. Isto quer dizer que não são um simples extrato de conjuntos de elementos obtidos da experiência bruta. Pode-se dizer que a mente humana não é um depósito de representações do mundo retratadas no léxico, cujas unidades lingüísticas operariam como rótulos (cf. Mondada, 1994:89).

\section{NOÇÃO DE COERÊNCIA}

A coerência , mais do que que uma propriedade do discurso, é uma espécie de condição discursiva, ou seja, um princípio. Não um princípio de boa-formação e sim um princípio de acessibilidade. Em certo sentido, podemos dizer que a coerência é o que deve acontecer quando introduzimos um certo objeto de discurso e depois pretendemos prosseguir com ele naquele discurso. A coerência é uma necessidade e uma condição da discursividade e não um simples produto de relações ou de atividades lingüísticas e lógicas.

Voltando ao exemplo de Chapeuzinho Vermelho, o que se pode notar é que aquele texto só se torna interessante na oposição a um outro texto acessível e nesta oposição todo o processo discursivo e a proposta de coerência se dão num contraponto àquela narrativa anterior com a qual essa nova versão dialoga. Não notamos a falta da mãe da menina, da cestinha de comida, do caçador (ou lenhador, dependendo da versão), nem da lição moral final e muito menos de toda a trama envolvendo os cuidados a que a menina sempre é submetida pela família preocupada. Não há heróis e resta muito pouco da história original. No entanto, nós a entendemos como uma forma de derivação e, nesse processo discursivo de derivação, se acha todo o segredo da coerência (ou do fio condutor) da nova versão.

De certo modo, pode-se dizer que a coerência é uma condição de acessibilidade intersubjetiva entre os produtores e receptores de discursos, desde que estejam interagindo colaborativamente. 
Ao indagar-se: “o que é um texto 'coerente'?”, Coates (1995:42) responde que isto depende de como definimos 'coerência'. Aceitando como correta essa postura metodológica, a posição central aqui admitida é a de que mais do que um fenômeno que se estabelece apenas na relação pertinente imediata entre enunciados (proposições, tópicos etc.) seqüenciados, a coerência decorre de atividades que relacionam dados (conhecimentos, enunciados, tópicos etc.) nem sempre imediatamente seqüenciados ou diretamente relacionados. Portanto, coerência não é uma relação de relevância imediata.

Embora não negue a validade dos princípios gerais da coerência propostos por Reinhart (1980), exigindo conexão estrita de um enunciado com o imediatamente anterior; consistência lógica na sequiência dos enunciados e relevância tópica para que haja coerência textual, julgo que essa visão do fenômeno é restritiva e fundada exclusivamente numa perspectiva imanentista. ${ }^{7}$ Isto não quer dizer, porém, que a coerência não tenha a ver de maneira essencial com relações de pertinência, mas que as relações de pertinência, sejam elas de que tipo forem, não são necessariamente imanentes nem imediatas. Portanto, a coerência não se dá apenas como uma relação de pertinência entre duas ou mais proposições, mas como construção de relações de compatibilidade (em várias dimensões) entre fenômenos que podem ser muito diferenciados, nem sempre naturalmente ligados e não necessariamente evidentes. Em suma, a coerência não é uma questão de evidência lógica nem de evidência empírica, mas uma atividade cognitiva desenvolvida no discurso (inferencialmente ou não), envolvendo fatores internos e externos.

Para uma noção de coerência proveitosa parece mais correto postular que um texto/discurso se torna coerente (assumindo o texto como um processo) e não simplesmente que um texto/ discurso é coerente (na perspectiva do texto como produto). A coerência se constrói em virtude de relações de sentido internas e externas ao discurso, ou seja, não se dá na dependência exclusiva de relações léxico-gramaticais ou lógicas.

Citando Wittgenstein, Givón (1995:75) lembra que a coerência máxima se manifestaria em seqüências tautológicas (repetições ou redundâncias), ao passo que a coerência zero ocorreria na presença de contradições. Entre estas duas posições extremas dentro de uma gradação de coerência de zero a um, teríamos pontos intermediários e sua determinação dependeria mais de realidades mentais (externas ao discurso) do que de realidades estritamente lingüísticas. Contudo, essas relações estariam sempre mediadas por elos representados por proposições, fatos etc. em que a atividade referencial constituiria uma espécie de base. É neste ponto que se situa a relevância da referenciação como uma das fontes desses elos.

Toda vez que um dado elemento é (lexicalmente ou não) introduzido, ele pode ser constantemente retomado por uma série de recursos léxico-gramaticais e manter assim a referência, permitindo com isto a construção de uma relação mentalmente recobrável pela memória discursiva. Esta continuidade será estabelecida por um elemento pronominal (anaforicamente) numa posição adjacente ou em distância média, mas de um certo ponto em diante a reativação exigirá a repetição lexical ou um item lexical associativamente relacionado (ou sinônimo). Observe-se, por exemplo, o caso (2), acima referido, em que a questão é continuada pela repetição de elementos lexicais presentes na primeira parte. A referenciação, como fio condutor de base, contribui tanto para a formação de relações locais como para o estabelecimento de canais temáticos e para a construção de representações globais.

${ }^{7}$ Mais adequada que a posição de Reinhart (1980) parece ser a posição de Hobbs (1979), segundo apontam Sanford \& Moxey (1995:163) ao lembrarem que muitas vezes a coerência é fruto de um trabalho do leitor/ouvinte de um texto que realiza conexões necessárias para produzir a compreensão. Conexões essas derivadas de uma atividade global e não localizada como postula Reinhart (1980). 
Cadernos de Estudos Lingüísticos 48(1) - Jan./Jun. 2006

Segundo Givón (1995:75-76), a coerência situada em algum ponto intermediário entre os extremos da tautologia e da contradição obedeceria a alguns princípios restritivos do tipo:

1. restrição da informação nova: (seqüências frasais em textos naturais tendem a ter apenas uma informação nova (em geral um item lexical) por frase);

2. restrição da informação velha: (sequiências frasais em textos naturais tendem a ter pelo menos uma informação velha em cada frase);

3. base múltipla, coerência e acesso mental; (quanto mais conexões de base uma frase tiver, tanto maior o acesso mental e tanto mais coerente tende a ser o texto em que se acha inserida).

Se considerarmos o princípio (2.), teremos aí o que Givón denomina "requisito de fundo mínimo", isto é, sem a presença da coerência referencial, não é possível a coerência discursiva de um modo geral. O princípio (3.) nada mais é do que a junção dos dois primeiros numa maximização de sua potencialidade. Estes três princípios seriam ideais se não estivessem situados no nível da frase. Este é o seu problema, de maneira que não os julgo adequados se tomados neste plano e sim se vistos no processo discursivo mais amplo.

Quanto ao aspecto que acaba de ser apontado, parece de extrema importância que um discurso, seja ele falado ou escrito, deve necessariamente preencher o requisito de topicalidade fundada na referenciação continuada, seja ela na base pronominal ou na base lexical. Pode haver lacunas preenchíveis por atividades cognitivas e investimento de conhecimentos externos. Podem ocorrer relações globais, ou seja, de extensões maiores ou outros aspectos que exijam maior esforço interpretativo. O que não pode faltar é uma base referencial preservada que permita a construção da coerência. É nisto que reside a possibilidade de identificar sobre o que se fala, ou então, se em dado momento, se volta a falar sobre o mesmo tópico já apresentado.

\section{REFERENCIAÇÃO E COERÊNCIA}

Referência e coerência apontam para dois aspectos centrais da produção de sentido no texto. Ambos são de algum modo co-dependentes, não se podendo determinar uma hierarquia de relevância entre ambos. Contudo, embora se interpenetrem, são duas noções bastante diversas. Há casos em que a referenciação de um elemento só é inferível a partir de estratégias globais sugeridas por atividades mentais como no caso de referentes de pronomes sem antecedente explícito. Há casos em que a coerência fica na dependência de relações referenciais estabelecidas no texto. E casos em que tudo depende de conhecimentos prévios em alto grau.

Grosso modo, pode-se dizer que a referência providencia pistas sugestivas para a produção de sentido e a coerência é o aproveitamento dessas sugestões para elaboração de sentidos específicos em modelos representacionais. Não se pode, no entanto, supor que a referenciação seja um processo tipicamente bottom-up e a coerência top-down. Isto seria identificar processos locais para a referência e processos globais para a coerência. Certamente, haverá casos em que a inferenciação dependerá de uma atividade global e não se dá por relações imediatas nem na simples identificação de referentes. Isto sugere que em boa medida dos casos, coerência e referenciação são atividades imbricadas e essencialmente co-determinadas, realizando-se tanto global como localmente.

Exemplo típico para esta última situação são os famosos resumos de novelas nos jornais. Esses resumos diários ou semanais são altamente complexos em relação a conhecimentos 
prévios, pois são fundados em pequenos fatos, todos seqüenciados e que situam o leitor no contexto de uma trama que já dura por vezes há mais de meio ano. Sob o ponto de vista de sua coerência, estes resumos são coerentes, mas para um leitor que não acompanha a novela ou não tem informações sobre aqueles fatos, tudo se passa no maior mistério. A coerência desses textos depende de informações tópicas e não apenas de relações discursivas.

Vejam-se estes poucos casos para uma idéia mais clara do problema: ${ }^{8}$

\section{(Exemplo 6)}

\begin{tabular}{|c|c|}
\hline $\begin{array}{l}\text { (1) } \\
\text { Marina diz que comprou o cachorro e que o resto do } \\
\text { dinheiro foi roubado. Toni Tiger decide ficar na } \\
\text { Malhação desde que não sofra assédio. Fabinho foge } \\
\text { da conversa com Carla. No quarto de Mocotó, Marina } \\
\text { conversa com Toni e os dois ficam amigos. No } \\
\text { Desabafo da Galera, a fama é o tema. Priscila trata } \\
\text { Robson friamente. }\end{array}$ & $\begin{array}{l}\text { (3) } \\
\text { Thiago não tira os olhos de celi e Valéria percebe. } \\
\text { Valéria larga Thiago na cama sozinho porque ele está } \\
\text { desligado. Chico encontra uma irmã da enfermeira } \\
\text { Helga. Janete enfrenta San Marino e avisa que vai } \\
\text { pedir um exame de DNA. Ana Paula tenta seduzir } \\
\text { San. Chico descobre que Helga foi casada com Tião } \\
\text { Alemão. }\end{array}$ \\
\hline $\begin{array}{l}\text { Diva sustenta a história que inocenta Alice. Abelardo } \\
\text { hospitaliza Higino na estalagem. Alice pede para } \\
\text { continuar na Ouro Verde. Olívia finge sentir desprezo } \\
\text { por Mariano e Higino permite que ele seja chamado } \\
\text { apara cuidar de Bárbara. Rosália se lembra do sumiço } \\
\text { e reaparecimento das roupas de Ester no dia do } \\
\text { casamento de Inácio. }\end{array}$ & $\begin{array}{l}\text { (4) } \\
\text { O delegado interroga Marcelo, que tenta se livrar das } \\
\text { acusações. Valdomiro se irrita ao ver Mauro em sua } \\
\text { casa. Márcia e Uálber, na ante-sala, contam toda a } \\
\text { verdade para Eleonor, que se desespera. Adriana } \\
\text { maltrata Fortunato. Eliseu chega ao aeroporto e diz ao } \\
\text { delegado que é o falsificador do quadro que está com } \\
\text { o Marcelo. }\end{array}$ \\
\hline
\end{tabular}

Estes quatro textos são um fragmento de quatro novelas em algum de seus momentos (alguns capítulos que se passam num certo dia). Quem não acompanha as novelas não tem o acesso cognitivo necessário para montar o quebra-cabeça dessas seqüências. Mas para quem acompanha as novelas tudo está muito claro. Isto nos faz pensar na coerência como uma atividade que se assemelha à solução de um problema, o que exige um contínuo reajuste. Está submetida a inferenciações sucessivas comandadas parcialmente pelas evidências textuais e parcialmente por realidades mentais. Dinâmica por natureza, a coerência é em boa medida uma construção cuja responsabilidade cabe também ao receptor, sendo assim um fenômeno que se dá negociadamente. Não se acha inscrita no texto, mas submete-se a um conjunto de indicadores primariamente textuais. Sua característica básica é não depender de relações textuais imediatas, mas de atividades cognitivas mediadoras. Guiada, pois, primeiramente pelo controle textual, não se prende à sua imanência e resulta de processamentos complexos relativos a aspectos internos e externos ao texto. Entre os aspectos internos mais relevantes está a referenciação.

${ }^{8}$ Os textos aqui são resumos de novela aparecidos no suplemento "Revista da TV" do Diário de Pernambvauco de 29/08/1999, das seguintes novelas: (1) Malhação (Globo), resumo para 3/09; (2) Força de um Desejo (Globo) resumo para 04/09; (3) Andando nas Nuvens (Globo), resumo para 04/09 e (4) Suave Veneno (Globo), resumo para 04/09. 


\section{Em suma:}

Para a análise da relação entre referenciação e coerência, será essencial considerar que, numa perspectiva macro, um texto constrói-se e progride com base em dois processos gerais: (1) progressão referencial e (2) progressão tópica. Esclarecendo as relações de diferença e semelhança entre os dois processos, pode-se lembrar, grosso modo, que a progressão referencial diz respeito à introdução, identificação, preservação, continuidade e retomada de referentes textuais, correspondendo às estratégias de designação de referentes e formando o que se pode denominar cadeia referencial. A progressão tópica diz respeito ao(s) assunto(s) ou tópico(s) discursivo(s) tratado(s) ao longo do texto. Contudo, se a continuidade referencial serve de base para o desenvolvimento de um tópico, a presença de um tópico oferece tão somente as condições possibilitadoras e preservadoras da continuidade referencial, mas não a garante.

A progressão referencial se dá com base numa complexa relação entre linguagem, mundo e pensamento estabelecida centralmente no discurso. A questão é complexa porque um texto não costuma ser monotópico, linear e homogêneo, especialmente quando tem uma extensão maior. Com isto, pode-se dizer que a continuidade tópica ao longo de um texto não é condição necessária para a progressão referencial. Por outro lado, parece ser intuitivamente verdadeiro que há uma relação de "quase-reciprocidade" entre manutenção de referentes e construção de tópicos discursivos.

\section{REFERÊNCIAS BIBLIOGRÁFICAS}

APOTHÉLOZ, D. (1995). Nominalisations, réferents clandestins et anaphores atypiques. In.: BERRENDONNER, A. e M-J. REICHLER-BEGUELIN (eds). 1995: 143-173.

APOTHÉLOZ, D. e M-J. REICHLER-BÉGUELIN. (1995). Construction de la référnce et strategies de designation. In.: BERRENDONNER, A .e M-J. REICHLER-BÉGUELIN (eds.), 1995:227-271.

BEAUGRANDE, R. de 1997. New Foundations for a Science of Text and Discourse: Cognition, Communication, and the Freedom of Access to Knowledge of Society. Norwood, New jersey, Ablex.

BERRENDONNER, A. (1995). Anaphore associative et méréologie. Recherches sur la Philosophie et le langage, $16: 237-255$.

BERRENDONNER, A. e REICHLER-BÉGUELIN, M.-J. (1995). Accords "associatifs". Cahiers de Praxématique, 24 (1995): 21-42.

BROWN, P. \& YULE, G. (1983). Discourse Analysis. London, Oxford Press.

DIJK, T. V. (1977). Text and Context. Explorations in the Semantics and Pragmatics of Discourse. London, Longman.

FAUCONNIER, G. (1997). Mappings in Thought and Language. Cambridge, Cambridge University Press

KLEIBER, G. (1994). Anaphores et pronoms. Louvai-la-Neuve, Duculot.

KLEIBER, G./ C. SCHNEDECKER / L. UJMA. (1994). "L'anaphore associative, d'une conception l'autre". In: Schnedecker, C. et alii (eds) (1991): 5-64. 
MARCUSCHI - Referenciação e progressão tópica...

KOCH, I. V. et alii. (1990). Aspectos do processamento do fluxo da informação no discurso oral dialogado. In: A.T. de CASTILHO (Org.) 1990. Gramática do Português Falado. Vol 1: A Ordem. Campinas, Editora da UNICAMP/FAPESP, pp. 143-184.

LEVINSON, S. (1987). Pragmatics and the grammar of anaphora: a partial pragmatic reduction of binding and control phenomena. Journal of Linguistics, 23:379-434.

MARCUSCHI, L. A. (1998). Aspectos da progressão referencial na fala e na escrita no português do Brasil. Apresentado no I Colóquio Internacional de Língua Portuguesa, Berlim, março de 1998. (no prelo)

MARCUSCHI, L.A. e KOCH, I. V. (1998). Progressão referencial na língua falada. Gramática do Português Falado, vol.IX, no prelo.

MILNER, J.-C. (1982). Ordres et Raisons de Langue. Paris, Seuil.

MONDADA, L. (1994). Verbalisation de l'espace et fabrication du savoir. Approche linguistique de la construction des objets de discours. Lausanne - Université de Lausanne, Faculté de Lettres. Thèse pour obtenir le grade de docteus en lettres (671 pp.).

MONDADA, L. e DUBOIS, D. (1995). Construction des objets de discours et categorisation: une approche des processus de référenciation. In: BERRENDONNER, A. e M-J REICHLER-BEGUELIN (eds). 1995: 273-302.

ROSCH, E. (1978). Principles of Categorization, In: ROSCH E. \& B.B. LLYOD (eds.). Cognition and Categorization. New York, Wiley.

SANFORD, A. J e GARROD, Simon C. (1982). Towards a processing account of reference. In: ${ }^{a}$ FLAMMER e W. KINTSCH (eds). Discourse Processing. Amsterdam, North-holland Publishung Company. Pp. 100110.

SCHNEDECKER, C.; CHAROLLES, M.; KLEIBER, G.; DAVID, J. (eds). (1994). L'Anaphore Associative (Aspects linguistiques, psycholinguistiques et automatiques). Paris: Klincksieck.

TASMOWSKY-de RYCK, L. e VERLUYTEN, S.P. (1982). Linguistic Control of pronouns. Journal of Semantics, 1: 323-346.

TASMOWSKY-de RYCK, L. e VERLUYTEN, S.P. (1985). Control Mechanism of Anaphora. Journal of Semantics, 4: 341-370.

YULE, G. (1982). Interpreting anaphora without identifying reference. Jornal of Semantics, 1: 315-323. 